\title{
Variation of Precipitable Water Vapor derived from GNSS CORS Observations in Thailand
}

\author{
Paramee Meunram and Chalermchon Satirapod \\ Department of Survey Engineering, Faculty of Engineering, Chulalongkorn University, \\ Phyathai Road, Patumwan, Bangkok 10330, Thailand \\ e-mail: paramee.m44@gmail.com, chalermchon.s@chula.ac.th
}

\begin{abstract}
This research aims to study a distance variation of Precipitable Water Vapor (PWV) between CORS stations in Thailand using a Precise Point Positioning (PPP) technique. Nowadays, GNSS Continuously Operating Reference Stations (CORS) is not only used to obtain precise positioning applications but also plays an important role in meteorological applications. With a recent establishment of GNSS CORS around Thai region, the PWV can be accurately derived from these GNSS CORS data using the scientific Position and Navigation Data Analyst (PANDA) GNSS processing software. One-year period of GNSS CORS data collected between 1 January and 31 December 2016 are used in this study. The GNSS CORS data used in this study are gathered from various agencies, i.e. Chulalongkorn University, Department of Lands and Department of Public Works and Town \& Country Planning. However, a coverage distance from each GNSS CORS station for PWV estimations is not precisely determined for Thai region. This information can help reduce expenses in an installation and maintenance of meteorology sensors at each GNSS CORS. Therefore, this paper focuses on determining the distance variation of PWV between GNSS CORS stations and the coverage distance from each CORS for PWV estimations. The result shows that the coverage distance from each CORS station at $74 \mathrm{~km}$ or less can provide accurate PWV in Thai region.
\end{abstract}

\section{Introduction}

Electromagnetic waves are transmitted from satellites when the waves travel through the atmosphere reflection and refraction make waves travel faster or slower. The atmosphere that affects this travelling wave is the ionosphere and the troposphere. In this study, the Troposphere which is the lowest layer of the atmosphere and above the earth's surface at $50 \mathrm{~km}$. ( Bernhard Hofmann-Wellenhof, 2007) It consists of two components; namely, about $10 \%$ of dry part and $90 \%$ of wet part of the refraction in the atmosphere. Both components result in the arrivals of the receiver slower than the actual travelling time because the measured distance is longer than it should be. We can apply the error due to the atmospheres and convert to Precipitable Water Vapor (PWV). The deviation of the wave passing through the atmosphere depends on several factors, such as the direction of the satellite and the receiver, the distance traveled by the wave, the temperature and the atmospheric pressure. There are two approaches to estimating the vertical deviation from the Zenith Total Delay (ZTD): Precise Point Positioning (PPP) and Baseline Networking. The application of the Global Navigation Satellite System (GNSS) in meteorology is another option that can be used. This information can help to reduce costs in an installation and maintenance of meteorology sensors at each GNSS CORS.

Previous studies in Thailand confirmed that the PWV values could be accurately derived from GNSS observations (Kitpracha et al., 2017; Satirapod et al., 2011; Suwantong et al, 2017). However, in the meteorological applications for Thailand, no coverage area of Precipitable Water Vapor was measured at each station. It can be used as a guideline for determinations and analyses of Precipitable Water Vapor in order to establish GNSS CORS network to be part of site location determinations in term of distance and coverage dependent.

This preliminary study, aims to study was study and analyze the horizontal distances that affected the changes of the errors due to the atmospheric effects and determine variations of PWV due to distance between GNSS CORSs and their coverage area from each CORS effecting the PWV estimations in order to assist reducing meteorological equipment installation costs at GNSS CORS ground and could applied in other water related applications such as agricultures, water management and weather prediction.

\section{Observation Model}

\subsection{Precise Point Positioning (PPP)}

PPP technique is a positioning method to computer a precise positioning solution to a level of few centimeter level of accuracy. The mathematic model of this positioning algorithm is determined by using an ionosphere-free combination for pseudorange and carrier phase GNSS observations to eliminate the first 
order of Ionosphere effects. The simplified PPP observation equation is shown as:

$$
\begin{gathered}
P_{L 3}=\rho+c(d t-d T)+M(Z T D)+\varepsilon_{p} \\
\emptyset_{L 3}=\rho+c(d t-d T)+M(Z T D)+N \lambda+\varepsilon_{\varnothing}
\end{gathered}
$$

where $P_{L 3}$ and $\emptyset_{L 3}$ are ionosphere free combination of pseudorange and carrier phase observations, respectively. $\rho$ is geometry distance between a satellite and a receiver. $d t$ and $d T$ are a receiver clock error and a satellite clock error, respectively. $\mathrm{c}$ is the speed of light in a vacuum. $N$ is defined as ionosphere free ambiguity. $\lambda$ is ionosphere free wavelength. ZTD is tropospheric delay in zenith direction. $\varepsilon_{p}$ and $\varepsilon_{\varnothing}$ are the multipath error and observation noise of ionosphere free combination observation. ( Min Li, 2014) This paper focuses on ZTD value which is obtained from GNSS data using PPP technique. Therefore, ZTD can be converted to PWV. Additionally, in this PPP processing, the parameters to be determined are the distance between satellite and receiver $(\mathrm{x}, \mathrm{y}, \mathrm{z})$, receiver clock error $(d t)$ and ambiguity $(N)$.

\subsection{Tropospheric Delay}

The troposphere is the atmospheric layer up to around $\mathrm{km}$. from the earth surface. The troposphere is nondispersive medium at GNSS carrier frequencies; which mean, the effects on the GNSS signal transmission are independent from its operating frequencies. The effect of troposphere on GNSS signals makes an extra delay in the measurement when the signal travels from the satellite to receiver. This delay depends on the temperature, pressure and humidity depending on station location and seasons. (Zong-qiu, Ai-gong, Xinchao, \& Ji-shan, 2012) Two major delays effected at the troposphere layer are often modeled as: the dry (hydrostatic) and the wet (non hydrostatic) components to define their refractivity.

PANDA is a GNSS data processing software to obtain a tropospheric delay at receiver's slant path delay (SPD) from a mapping function multiply by zenith total delay. The Mapping function is related to Zenith Hydrostatic Delay (ZHD) and Zenith Wet Delay (ZWD). The slant total delay can be written as:

$$
\begin{aligned}
S P D= & Z T D \times M f(E)=Z H D \times M \operatorname{Mry}(E)+ \\
& Z W D \times M \operatorname{Met}(E)
\end{aligned}
$$

in which $M f$ is a total mapping function. Mdry and Mwet are mapping function for a dry part and wet part, respectively. $E$ is elevation angle, in degree.

Any empirical tropospheric delay models have been established, including Saastamonien model ( Saastamoinen, 1972), hence, it is determined to applied Saastamonien model as the empirical model in this estimations (Kouba, 2015) to obtain the ZWD which is the one of the factors to specify its accuracy in GNSS positioning solution. This is due to the fact that the precision of ZWD was estimated; therefore, it is essential for high precision application, such as PPP. This study applied; several processing strategies to determine the tropospheric delay. Furthermore, the ZWD was calculated and can be used in numerical weather predictions as specified in the equation below.

$$
Z W D=Z T D-Z H D
$$

The most common method to describe the wet delay is through a combination of surface measured parameters (including water vapor pressure, or relative humidity, and temperature). Currently, many tropospheric models for mitigating the tropospheric delay are available such as Saastamonien model which can be expressed as:

$$
Z H D=\frac{2.2768 \times P S}{1-0.00266 \cos (2 \varnothing)-0.00000028 H}
$$

where $P s$ is the pressure temperature (unit: millibar), $\varnothing$ is the station latitude (unit: radius) and $\mathrm{H}$ is the height of the station above the sea level (unit: meter).

Precipitation Water Vapor (PWV), retrieved from the national GNSS CORS network is used in weather forecastings. The PWV is the integrated amount of water vapor along the path between transmitting satellite and receiving antennas. The dimension quantity $(\pi)$ depends on the mean temperature's weight of atmosphere and be calculated from the empirical model. (MICHAEL BEVIS, 1992)

$$
P W V=\pi \times Z W D
$$

The unit of PWV is millimeter (mm.) because the PWV content of this column equals the amount of water if all water vapor was condensed. The commonly used units are $[\mathrm{kg} / \mathrm{m} 2]$ reflecting the weight of the condensed water or $[\mathrm{mm}]$ if water is accumulated on the bottom of the column.(EUMeTrain, 2014)

$$
\pi=\frac{10^{6}}{\rho w \times R v\left(\frac{k 3}{T m}+k^{\prime} 2\right)}
$$

in which $\pi$ is a dimensionless constant of proportionality, $\mathrm{Tm}$ is mean of temperature and $\mathrm{Tm}$ was estimated Empirical Model by Global Mapping Function (GMF). $\rho w$ is the density of liquid water $\left(999.97 \mathrm{~kg} . \mathrm{m}^{3}\right) . R v$ is the constant of water vapor (461.525 $\left.\mathrm{JK}^{-1} / \mathrm{kg}^{-1}\right) . k 3$ and $k^{\prime} 2$ are the physical constant derived by several laboratories with value $3739 \mathrm{k}^{2} / \mathrm{mb}$ and $22.1 \mathrm{k} / \mathrm{mb}$., respectively.

$$
T_{m}=70.2+0.72 \times T_{s}
$$

In this study, the mean temperature $\left(T_{m}\right)$ and surface pressure $\left(T_{S}\right)$ are determined from Global Pressure and Temperature (GPT) model used to estimate mean of temperature and surface pressure (unit: kelvin) respectively. (see more information from this link: http://ggosatm.hg.tuwien.ac.at/DELAY/SOURCE/gpt. m.) 


\section{Methodology}

\subsection{PPP Processing}

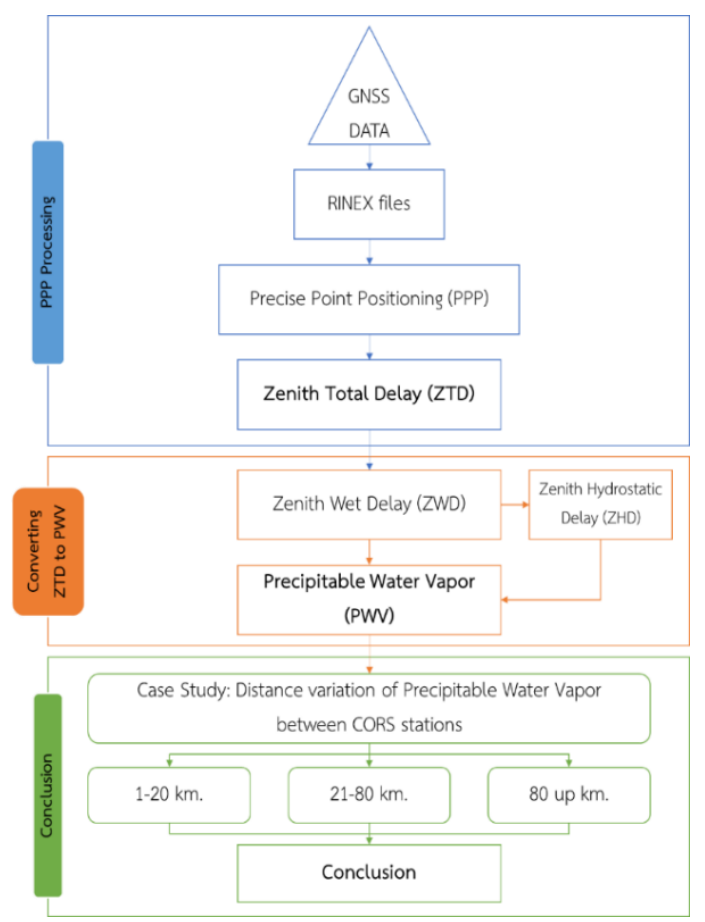

Fig. 1. Data processing step

In this paper, PPP technique is selected to calculate ZTD by PANDA software. The data processing steps are as followings. Firstly, observation data preparations, GNSS observation are obtained from 10 GNSS reference stations known as GNSS data; defined as Chulalongkorn University (CUUT), Ayutthaya (AYYA), Nakhon Nayok (OKRK), Nakornpatom (BLAN), Nonthaburi (PKKT) Samut Sakhon (KTBN), Saraburi (KKOI), Samut Prakan (BPLE), Bangkok (DTP9) and Nakhon Sawan (NKSW). These GNSS data is later regenerated using TEQC toolkit by UNAVCO to decimating observations in a RINEX file by the original sample interval is 1 second to decimated to 30 -second interval observations. Secondly, PANDA software is originally developed by Wuhan University that has achieved their the advancement the world class. This PPP processing allows some settings to be included in the precise solution such as satellite orbit error, satellite clock offset, Phase Center Offset (PCO), Phase Center Variation (PCV) and solid earth tide \& Ocean loading. (Kouba, 2015)

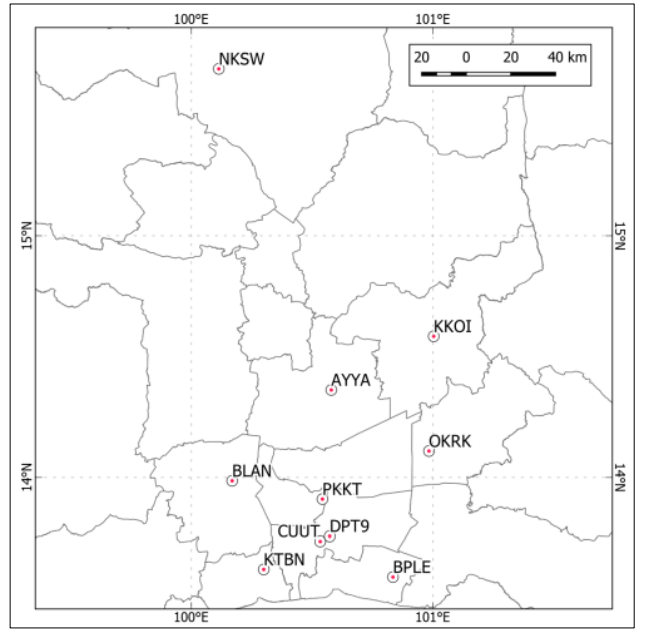

Fig. 2. Local distribution of GNSS Stations selected for this study. For these stations, we have collected GPS observation between January 1st and December 31st, 2016

\subsection{Converting ZTD to PWV}

The ZTD derived from PPP can be expressed in two components comprised of Zenith Hydrostatic Delay (ZHD) and a Zenith Wet Delay (ZWD). The ZHD can achieve better accuracy by obtaining some measurements from surface meteorological data. However, the ZWD is commonly used as an estimated parameter to obtain higher accuracy due to a high variation and can be transformed into PWV when a mean temperature $\left(T_{m}\right)$ is realized. The ZWD can be expressed in terms of the ZTD and ZHD. (Bevis et al., 1992)

\subsection{Data Analysis}

The GNSS observation data and International GPS service (IGS) final products are used in this data analyses. The PANDA software calculates the double difference between GPS transmitter and receiver clock error. The Slant Path Delay is later computed into vertical precision or ZTD the previously determines results using PPP (as described in Section 3.2). ZTD observations are results provided from the GPS processing solution. ZTD had to be later converted to the PWV (as described in Equation 4). The results from the previous determination are summarized in standard deviation (S.D.) of PWV. The differences of PWV S.D. are compared with variations in distances due to distance variations of precipitable water vapor between GNSS CORSs could be provided to the best benefit in term of providing precipitable water vapor. 


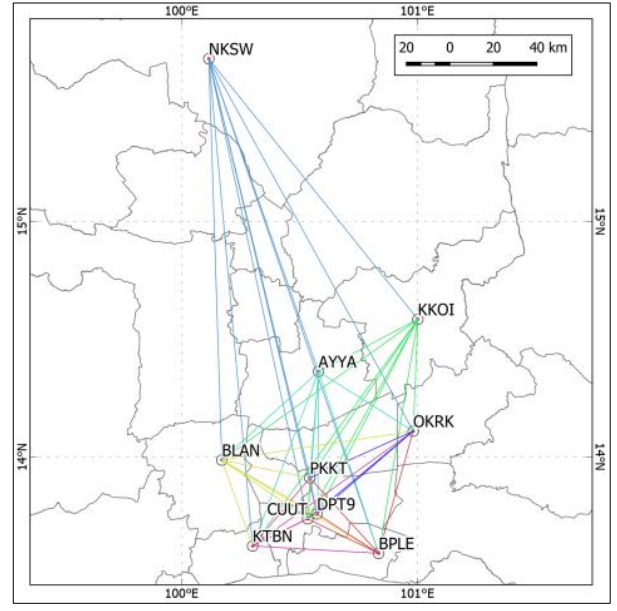

Fig 3. The all possible combinations of 10 stations.

\section{Result}

\subsection{Variation of PWV}

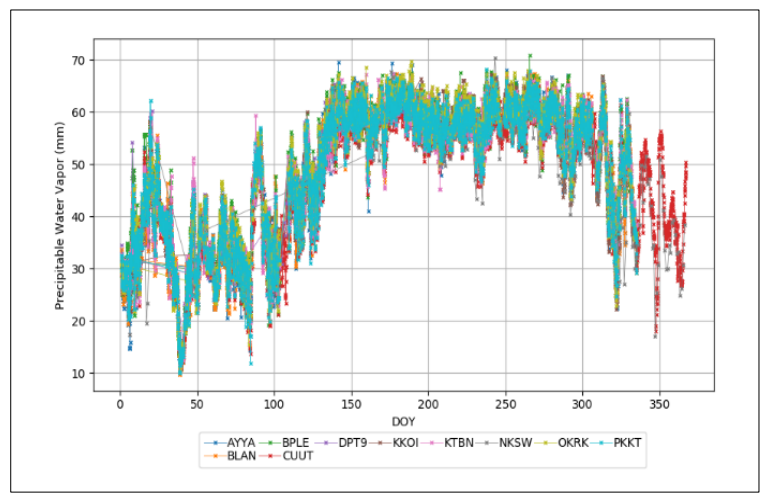

Fig. 4. Precipitable Water Vapor (PWV) in 2016

The scatter plot of the PPP-derived PWV time series between January and December in 2016 using IGS orbit and clock products from 10 stations is shown in Figure 4. The PPP-derived PWV time series are resampled at the interval of 2 hours. The results showed that the PWVs varied from 10 to 70 millimeters through this year. In Thailand, there are 3 seasons in a year: summer, rainy and winter. The summer period runs from mid-March to mid-May, with April and May the hottest months of the year. Consequently, the large amount of the PWVs continually increased from about 30 to 60 millimeters between DOY 100 to DOY 150 (see Figure 4). During this period of a year, the influence of changing season from northeast monsoon season to the southwest monsoon season which brings a large quantity of rainfall in this area. The rainy season runs from midMay to mid-October. The amount of the PWVs in this period varied from about 50 to 70 millimeters and the winter season runs from mid-October to mid-March because of the northeast monsoon bringing relatively cool and dry condition to Thailand. Thus, the amount of PWVs decreased from 60 to 30 millimeters.

\subsection{Determining the distance variation of PWV between GNSS CORS}

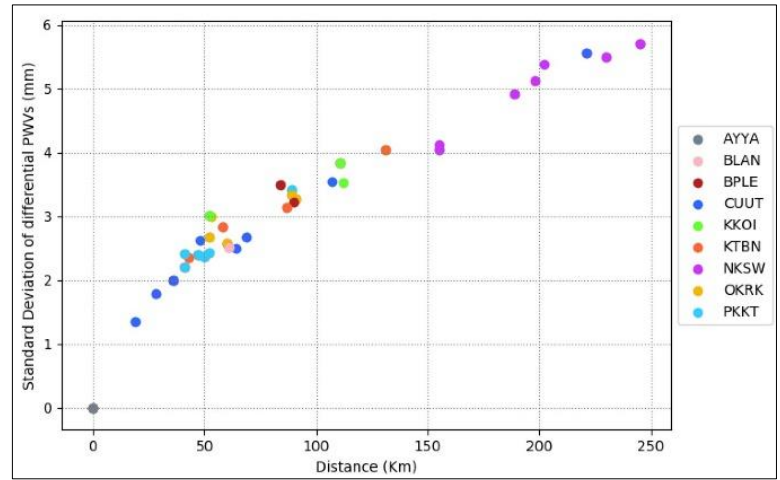

Fig. 5. Variations of SD of differential PWV and its corresponding distances between GNSS CORSs

In order to determine the coverage distance of the PWVs from each CORS stations, the PWVs from each station were compared at the same epoch. The number of all possible combinations of 10 stations are 45 . Figure 5 displayed a comparison of variation between S.D. of differential PWVs and its distance, The S.D. of Differential PWVs (mm.) is compared with the GNSS referenced station distance $(\mathrm{km}$.). The results show that S.D. of PWVs is increased when the distance changes. The PWV uses its S.D. to show the distribution of the computed PWV. The S.D. of PWVs in the atmosphere begins to change significantly at any distance. The results of the analysis show that:

- The first test case assigns the distance to be ranges from $1 \mathrm{~km}$ to $20 \mathrm{~km}$. The averaged S.D. of PWV is approximately $2.20 \mathrm{~mm}$.

- The second test case assigns the distance to be ranges from $21 \mathrm{~km}$ to $80 \mathrm{~km}$. The S.D. is scattered, S.D. is higher than the first test case. Their averaged SD was $2.69 \mathrm{~mm}$. The data on the amount of steam in the atmosphere between the stations start to be varies.

- The third test case assigns the distance to be ranged more than $80 \mathrm{~km}$. The data spreads more when the distance between stations is in the same trend as for the second case. The data difference is approximately $4.3 \mathrm{~mm}$.

This analysis could use CUUT; a reference station, as an example. It results that S.D. of differential PWVs (mm.) were compared to the distance of CORS for a whole year. The results are shown in Table 1 where each station which is compared with every other station with its relative distances and corresponding S.D. of its differential PWV, hence, the difference in variation in distances are provided. The figure 6, X-axis is Distance $(\mathrm{km}$.$) and the \mathrm{Y}$-axis is its corresponding Standard deviation of differential PWVs (mm.) 
Table 1. Distance from the reference station (CUUT)

\begin{tabular}{|c|c|c|c|}
\hline \multicolumn{2}{|c|}{ Stations } & $\begin{array}{c}\text { Distance } \\
(\mathbf{k m} .)\end{array}$ & S.D. \\
\hline \multirow{4}{*}{$\begin{array}{c}\text { CUUT } \\
\text { (Reference }\end{array}$} & DPT9 & 5 & 2.36 \\
\cline { 2 - 4 } Station) & PKKT & 19 & 1.35 \\
\cline { 2 - 4 } & KTBN & 28 & 1.79 \\
\cline { 2 - 4 } & BPLE & 36 & 2.00 \\
\cline { 2 - 4 } & BLAN & 48 & 2.62 \\
\cline { 2 - 4 } & OKRK & 64 & 2.49 \\
\cline { 2 - 4 } & AYYA & 69 & 2.67 \\
\cline { 2 - 4 } & KKOI & 107 & 3.55 \\
\cline { 2 - 4 } & NKSW & 221 & 5.56 \\
\hline
\end{tabular}

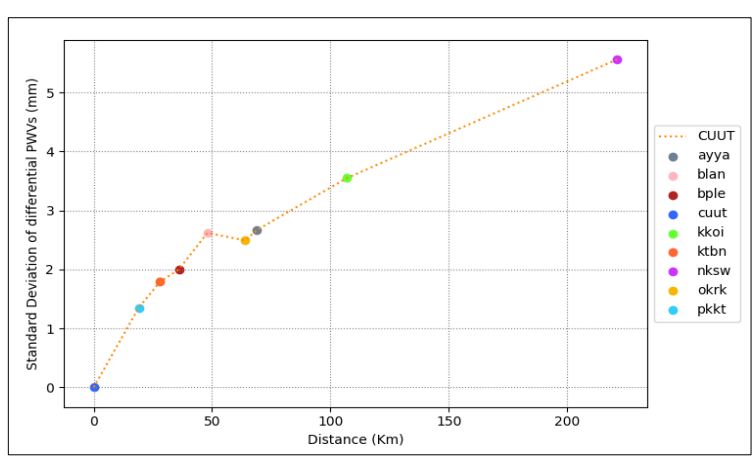

Fig. 6. S.D. of differential PWVs (mm.) of CUUT station

In the computation step, Linear Regression Analysis was used for approving the equation to determined its suitable for the analysis. The distances between GNSS CORS should not exceed $74 \mathrm{~km}$. in Thailand. The result of this study obtained from polynomial equation that is

$$
y=0.00008 * x 2+0.03988 * x+0.47367
$$

The reason for 74 is the answer to this study because the differential of PWVs between CORS should not exceed its difference of to $3 \mathrm{~mm}$. (Haan, 2006) and is in-lined with the substation results from the above where $\mathrm{x}$ is the GNSS CORS distance and $\mathrm{y}$ is the difference of PWV. In the case, when the differences of PWV (in term of y) as 3, the result of distance (in term of $x$ ) is approximately 74 . It could be confirmed as the answer of this study that distance should not exceed 74 $\mathrm{km}$. for GNSS CORS's establishment in Thailand. Furthermore, this polynomial equation is defined at $95 \%$ confident level at the R-squared test which means the factor 2 of its standard deviations which considered enough for the desired reliability.

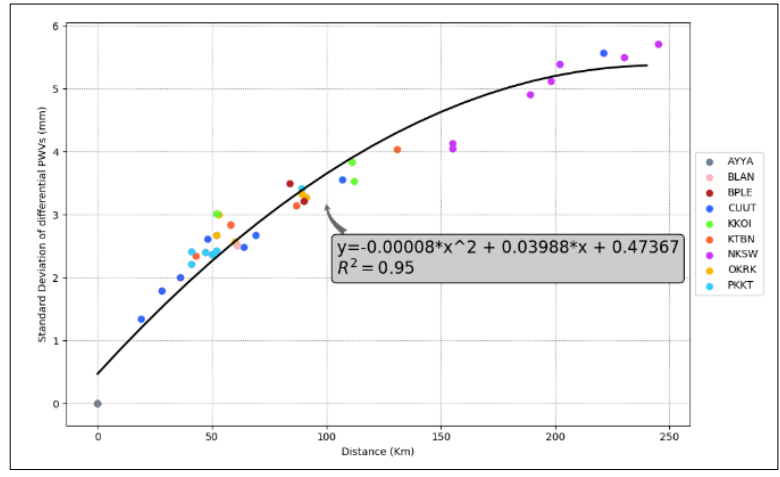

Fig. 7. A $2^{\text {nd }}$ order polynomial trendline was used to illustrate the relationship between the S.D. of the differential PWVs between stations.

\section{Conclusion}

This study determines the distance between GNSS CORS that affects the PWV estimations in central part of Thailand. It found that the relationship of the distance between the GNSS CORS and the PWV's distribution can be expressed as quadratic polynomial equation. The polynomial equation could be expressed as $y=0.00008 * x^{2}+0.03988 * x+0.47367$, where the acceptable PWV component should not be greater than $3 \mathrm{~mm}$. (or $\mathrm{y} \leq 3$ ). The distance between each reference stations is $74.47 \mathrm{~km}$ as, determined; hence, the distance between the station in central part of Thailand should be within $74 \mathrm{~km}$.

\section{References}

1. Bevis, M., Businger, S., Herring, T. A., Rocken, C., Anthes, R. A., and Ware, R. H. (1992) GPS Meteorology - Remote-sensing of atmospheric water-vapor using the global positioning system. Journal of Geophysical Research-Atmospheres, 97(D14), 15787-15801.

2. Bernhard Hofmann-Wellenhof, H. L. (2007)

GNSS - Global Navigation Satellite Systems. In SpringerWienNewYork.

3. Haan, S. d. (2006) National/regional operational procedures of gps water vapour networks and agreed international procedures.

4. Kitpracha, C., Promchot, D., Srestasathiern, P. and Satirapod, C. (2017) Precise Tropospheric Delay Map of Thailand using GNSS Precise Point Positioning Technique, International Journal of Geoinformatics, 13(2), 17-21.

5. Kouba, J. (2015) A Guide to Using the IGS Products. International GNSS Service (IGS).

6. Michael bevis, S. B. (1992) GPS Meteorology' Remote Sensing of Atmospheric Water Vapor Using the Global Positioning System. Journal of geophysical research, 97.

7. Min Li, L. Q. (2014) Precise Point Positioning Using PANDA Software Package. GNSS Research Center,Wuhan University. 
8. Wu (1993) Effects of antenna orientation on GPS carrier phase. Manuscripta Geodaetica, 91-98.

9. Saastamoinen, J. (1972) Atmospheric Correction for the Troposphere and Stratosphere in Radio Ranging Satellites. In S. W. Chovitz, Geophysical Monograph Series. doi:https://doi.org/10.1029/GM015p0247

10. Satirapod C., Anonglekha S., Choi Y-Sand Lee HK (2011) Performance Assessment of GPS-Sensed Precipitable Water Vapor in Thailand Using IGS Ultra-rapid Orbits, Engineering Journal, 15(1), 18.

11. Suwantong, R., Srestasathiern, P., Satirapod, C., Chuang, S. and Kitpracha, C. (2017) Mean atmospheric temperature model estimation for GNSS meteorology Using AIRS and AMSU data, Engineering and Applied Science Research, 44(1), 46-52.

12. Zong-qiu, X., Ai-gong, X., Xin-chao, and Ji-shan, L. (2012) Research on the Correlation of Troposphere Delay Parameters in GPS. Advances in Information Sciences \& Service Sciences. 